\title{
Characterization of a short-term culture from a canine diffuse gastric carcinoma
}

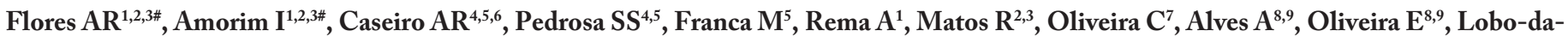 \\ Cunha $A^{9}$, Porto $B^{7}$, Colette Maurício $A^{4,5}$, Seixas $F^{10}$ and Gartner $F^{1,2,3 *}$ \\ ${ }^{1}$ Department of Pathology and Molecular Immunology, Institute of Biomedical Sciences Abel Salazar (ICBAS), University of Porto (UP), Rua Jorge Viterbo Ferreira \\ nr. 228, 4050-313 Porto, Porto, Portugal \\ ${ }^{2}$ Institute for Research and Innovation in Health (i3S), University of Porto (UP), Rua Alfredo Allen, 4200 - 135 Porto, Portugal \\ ${ }^{3}$ Institute of Molecular Pathology and Immunology (IPATIMUP), University of Porto (UP), Rua Dr. Roberto Frias s/n, 4200-465 Porto, Portugal \\ ${ }^{4}$ Center of Animal Science Studies (CECA), Institute of Sciences, Technologies and Agroenvironment, University of Porto (ICETA), Praça Gomes Teixeira, \\ Apartado 55142, 4051-401, Porto, Portugal \\ ${ }^{5}$ Department of Veterinary Clinics, Institute of Biomedical Sciences Abel Salazar (ICBAS), University of Porto (UP), Rua Jorge Viterbo Ferreira nr. 228, 4050-313 \\ Porto, Portugal \\ ${ }^{6}$ REQUINTE/LAQV, Department of Metallurgical Engineering and Materials, Faculty of Engineering, University of Porto (UP), Rua Dr. Roberto Frias, s/n, \\ 4200-465 Porto, Portugal \\ ${ }^{7}$ Laboratory of Cytogenetics, Institute of Biomedical Sciences Abel Salazar (ICBAS), University of Porto (UP), Rua Jorge Viterbo Ferreira nr. 228, 4050-313 Porto, \\ Portugal \\ ${ }^{8}$ Unit for Multidisciplinary Biomedical Research (UMIB), Institute of Biomedical Sciences Abel Salazar (ICBAS), University of Porto (UP), Rua Jorge Viterbo \\ Ferreira nr. 228, 4050-313 Porto, Porto, Portugal \\ ${ }^{9}$ Laboratory of Cell Biology, Institute of Biomedical Sciences Abel Salazar (ICBAS), University of Porto (UP), Rua Jorge Viterbo Ferreira nr. 228, 4050-313 Porto, \\ Portugal \\ ${ }^{10}$ Center of Animal and Veterinary Sciences (CECAV), University of Trás-os-Montes e Alto Douro (UTAD), Quinta dos Prados, apartado 1013, 5001-801, Vila \\ Real, Portugal \\ \#These authors contributed equally to this study.
}

\begin{abstract}
Canine gastric carcinomas share strong similarities with those occurring in humans, providing a useful resource to understand gastric carcinogenesis. For the first time, a short-term culture derived from a 14-years-old Golden Retriever dog with a metastatic gastric carcinoma is presented and characterized. Several assays were conducted to assess the morphological, molecular and genetic characteristics of the short-term primary culture. Cells grew in adherent monolayer, with a population doubling time of 45,88h and had been passaged over 7 times. Electron microscopy showed that cultured cells were round with irregular nucleus and prominent nucleoli. In culture, cells were positive for AE1/AE3 and vimentin and negative for E-cadherin immunomarkers. Karyotype demonstrated that the primary culture was predominantly aneuploid, further reinforcing its neoplastic nature. The short-term canine gastric cancer culture exhibited characteristics of the original neoplasm thus, representing a useful in vitro model for gastric cancer research in dogs.
\end{abstract}

\begin{abstract}
Abbreviations: HGCs: Human gastric carcinomas; CGCs: Canine gastric carcinomas; H\&E: Haematoxylin and eosin; PAS-AB Periodic acid Shiff plus Alcian blue, ON: Overnight; E-cad: E-cadherin; DPBS: Dulbecco's Phosphate Buffered Saline; Pen/strep: Penicillin-streptomycin solution; AMP: Amphotericin B; DMEM/F-12: Dulbecco's modified eagle medium nutrient mixture F-12 Ham; FBS: Foetal bovine serum; P: Passage; EMT Epithelial-to-mesenchymal transition; CIN: Chromosome instability.
\end{abstract}

\section{Introduction}

Gastric cancer is the fourth most common human cancer and the second leading cause of death in the world [1]. In dogs, gastric tumours are rare, representing $<1 \%$ of all reported neoplasms and among those, approximately $50-90 \%$ are carcinomas [2].

${ }^{*}$ Correspondence to: Fatima Gartner, ECVP (Dipl), PhD, MDV, Department of Pathology and Molecular Immunology of the Institute of Biomedical Sciences Abel Salazar (ICBAS), University of Porto. Rua Jorge Viterbo Ferreira nr.228, 4050-313 Porto, Portugal, E-mail: fgartner@ipatimup.pt

Key words: cancer, canine, diffuse gastric carcinoma, short-term primary culture, stomach

Received: January 12, 2019; Accepted: February 01, 2019; Published: February 04, 2019 
Canine gastric carcinomas (CGCs) show strong similarities to human's gastric carcinomas (HGCs) with respect to clinical presentation, histopathological features and disease progression [3]. Therefore, spontaneously occurring CGCs may provide a useful resource to understand gastric carcinogenesis, and to the development of new therapeutically approaches [4]. However, detailed investigations of gastric cancer in dogs are hampered by the lack of established in vitro models.

Cell lines derived from spontaneous tumours have been widely used for in vitro research and proved to be useful for both exploring the biological mechanisms [5], deregulated genes and signalling pathways underlying cancer [6,7]. Furthermore, these tools provide an alternative to direct xenotransplantation of tumours in animals for testing chemotherapeutics [8].

Currently, more than 40 human gastric cancer cell lines have been established from primary tumours [9-13], metastatic tumours $[9,10,14]$, ascites [9-11,14 and pleural effusions [14]. Primary cultures of normal canine gastric cells have been used for functional studies $[15,16]$ however, to the best of our knowledge, no canine gastric cancer cell line has been characterized.

In this report we describe and discus the results obtained by the morphological, chromosomal, molecular and genetic analysis of a short-term primary culture derived from an adult male dog with a diffuse gastric carcinoma.

\section{Materials and methods}

\section{Patient history, clinical diagnosis and outcome}

A 14-year-old neutered male Golden Retriever dog was referred to the ICBAS Small Animal Hospital with a history of one-week vomiting and decreased appetite. Hemogram and serum biochemistry were within the reference ranges and abdominal ultrasound showed no relevant changes. The animal was properly treated however, five days later the dog presented anorexia, diarrhoea and exuberant ptyalism. An endoscopy was performed, and gastric biopsies were sent to histopathologic examination. The histological diagnosis was undifferentiated gastric carcinoma with evident vascular invasion. Twelve days later, the owner declined further diagnostic and clinical care and requested the euthanasia of the animal. The necropsy exam and the collection of all biological samples were performed with prior informed consent of the owner, in accordance with the Animal Welfare Organization (ORBEA) of the ICBAS-UP (ORBEA Authorization N ${ }^{\circ}$ 201/2017).

\section{Necropsy, histopathology and immunohistochemistry}

Fresh samples from gastric neoplasia, lung, regional lymph nodes, pancreas, liver, adrenal gland and mesentery were removed during necropsy and fixed in $10 \%$ buffered formalin and paraffin-embedded. Serial consecutive $2 \mu \mathrm{m}$-sections were processed for routine staining (Haematoxylin and eosin: H\&E), histochemistry (Periodic acid Shiff plus Alcian blue: PAS-AB) and immunohistochemistry. The neoplasm was re-examined being classified according to the World Health Organization classification for alimentary tumours of domestic animals [17] and human Lauren classification for gastric cancer [18].

For immunohistochemistry, antigen retrieval was performed on dewaxed sections and the Novolink ${ }^{\mathrm{TM}}$ Max-Polymer detection system (Novocastra) was used for visualization. Slides were incubated with primary antibodies overnight $(\mathrm{ON})$ at $4^{\circ} \mathrm{C}$ (Tables 1 and 2). Positive controls consisted in sections of canine normal mammary gland. Normal gastric mucosa adjacent to the neoplasm was also used as internal positive control. Negative controls were performed by omission of the primary antibodies.

Immunohistochemistry expression was evaluated semiquantitatively based on the subcellular location, intensity (negative, weak, moderate, strong) and extent (negative, $<10 \%$ of positive cells, $10-50 \%$ of positive cells, $>50 \%$ of positive cells) of immunostaining. Additionally, the expression of E-cadherin (E-cad) was classified as: normal, when there was a membranous labelling at the lateral cellcell boundaries; and abnormal, when there was a loss of membranous distribution of staining [19].

\section{Tissue culture}

\section{Specimen collection and culture conditions}

Fresh samples from gastric neoplasm were also placed in transport solution containing Dulbecco's Phosphate Buffered Saline (DPBS, Gibco) supplemented with penicillin-streptomycin solution (100 $\mathrm{U} / \mathrm{ml}-100 \mathrm{mg} / \mathrm{ml})$ (Pen/Strep, Gibco) and amphotericin B (2.5 $\mu \mathrm{g} /$ $\mathrm{mL}$ ) (AMP, Gibco), for cell culture. A previously described method for isolation and culture of human gastric epithelial cells was applied [20]. Briefly, tissue was washed with DPBS, minced in 1-2 $\mathrm{mm}^{2}$ and decontaminated in Hank's Balanced Salt Solution (Gibco) containing Pen/Strep and AMP. Then, tissue was digested with $3 \mathrm{mg} / \mathrm{ml}$ of Dispase and $354 \mathrm{U} / \mathrm{ml}$ of Collagenase type I (Sigma) in Dulbecco's modified eagle medium nutrient mixture F-12 Ham (DMEM/F-12, Gibco) (1:1) supplemented with Pen/Strep and AMP, at $37^{\circ} \mathrm{C}$ for $1 \mathrm{~h}$. After, digested tissue was filtered through a cell strainer $(70 \mu \mathrm{m}$ pore size) and cells

Table 1. Data from primary antibodies used in the techniques applied in this study

\begin{tabular}{|c|c|c|c|c|c|c|}
\hline \multirow{2}{*}{ Marker } & \multirow{2}{*}{ Type/clone* } & \multirow{2}{*}{ Supplier } & \multicolumn{3}{|c|}{ Dilution } & \multirow{2}{*}{$\begin{array}{c}\text { Antigen retrieval for } \\
\text { IHQ }\end{array}$} \\
\hline & & & IHQ & IF & Western Blot & \\
\hline Pan-cytokeratin & Cocktail AE1/AE3 & Menarini & $1: 300$ & $1: 300$ & $1: 300$ & RS/WB \\
\hline Vimentin & $\mathrm{Mab} / \mathrm{V} 9$ & Dako & $1: 500$ & $1: 500$ & $1: 500$ & RS/WB \\
\hline E-cadherin & $\mathrm{Mab} / 4 \mathrm{~A} 2 \mathrm{C} 7$ & Invitrogen & $1: 50$ & - & - & Extran/MW \\
\hline E-cadherin & $\mathrm{Mab} / 24 \mathrm{E} 10$ & Cell Signalling & - & $1: 100$ & $1: 1000$ & - \\
\hline
\end{tabular}

(*Mab=monoclonal antibody; IHQ= Immunohistochemistry; IF= Immunofluorescence; RS= Retrieval Solution; WB=Water Bath; MW= Microwave; )

Table 2. Commercial culture media and their compositions in terms of glucose concentration and the addition of HEPES and Glutamax

\begin{tabular}{|c|c|}
\hline Culture medium & Composition \\
\hline MEM $\alpha$ & $1,000 \mathrm{mg} / \mathrm{ml}$ glucose and Glutamax \\
\hline RPMI640 & $2,000 \mathrm{mg} / \mathrm{ml} \mathrm{glucose} \mathrm{and} \mathrm{Glutamax}$ \\
\hline DMEM/LG & $1,000 \mathrm{mg} / \mathrm{ml} \mathrm{glucose} \mathrm{and} \mathrm{Glutamax}$ \\
\hline DMEM/F-12 & $3,151 \mathrm{mg} / \mathrm{ml}$ glucose, L-Glutamine and HEPES \\
\hline DMEM/HG & $4,500 \mathrm{mg} / \mathrm{ml}$ glucose and Glutamax \\
\hline
\end{tabular}


centrifuged at $1600 \mathrm{rpm}$, for $10 \mathrm{~min}$. Pelleted cells were resuspended in DMEM/F-12 (1:1) supplemented with 20\% foetal bovine serum (FBS, Gibco), Pen/Strep and AMP, seeded in a T25 culture flask (Sarstedt) and incubated in a humidified atmosphere with $5 \% \mathrm{CO}_{2}$ at $37^{\circ} \mathrm{C}$. The growth medium was replaced every 2 days. Cells were passed when reached $90 \%$ confluency, and the sequential trypsinization was used to obtain a pure tumour cell population. The cells were washed with DPBS, incubated with $0.25 \%$ trypsin with EDTA (Gibco) at $37^{\circ} \mathrm{C}$ for 5 min and then dispersed into a new flask, at concentration of $1 \times 10^{4}$ cells/ $\mathrm{cm}^{2}$, to further expansion. Cultured cells were routinely observed for fungal and bacterial contamination and tested at 12 and 24 days after isolation and plating of the cells, to microbial contamination using an automated culture system (BacT/ALERT ${ }^{\circ}$, BioMérieux) at $35^{\circ} \mathrm{C}$ for 14 days.

\section{Optimal growth cell culture conditions study}

To evaluate the optimal culture medium for cell proliferation, different commercially available media were tested. The known media composition is summarized in Table 2. All standard media were supplemented with 20\% FBS, Pen/Strep, AMP and (v/v) HEPES (Gibco) (exception to DMEM/F-12, which already has HEPES). Cells at passage 2 (P2) were seeded on a 24 -well plate (16.000 cells/well) and cell viability analysed by the Presto Blue cell viability reagent (Invitrogen) at $24 \mathrm{~h}, 72 \mathrm{~h}, 144 \mathrm{~h}$ and $192 \mathrm{~h}$, according to the manufacturer's protocol. At each time point, supernatant was transferred to a 96 well plate and absorbance was read at a wavelength of 570 and $595 \mathrm{~nm}$, on a Multiskan ${ }^{\mathrm{TM}}$ FC Microplate Photometer (ThermoScientific). The measurements were performed in triplicates for each growth medium. Corrected absorbance was obtained by the subtraction of average of the control wells to each experimental well.

\section{Growth properties experiments}

Growth assay: Cells at P4 were seeded on a 12-well plate $(32.000$ cells/well) and maintained in MEMa supplemented with $20 \%$ of FBS, Pen/Strep, AMP and HEPES at cell culture conditions, for 6 days. Every $24 \mathrm{~h}$, each well was trypsinized, the cells counted in triplicate and cell viability assessed by Trypan Blue exclusion assay using a Countess ${ }^{\text {Tw }}$ II FL Automated Cell Counter (Invitrogen). A growth curve was established and cell doubling time was calculated by logarithmic least squares fitting techniques [21].

Cell viability assay: Concurrently, cell viability was assessed by the Presto Blue cell viability reagent. Cells at P4 were plated in 96 well plate in quintuplicates, (2.000 cells/well) and maintained in MEMa supplemented with $20 \%$ of FBS, Pen/Strep, AMP and HEPES, for 6 days. Every day, cell viability was evaluated by the Presto Blue cell viability assay as described above. All measurements were made in triplicates.

\section{Morphological studies}

Cells were fixed for $2 \mathrm{~h}$ at $4{ }^{\circ} \mathrm{C}$ with $2.5 \%$ glutaraldehyde in $0.1 \mathrm{M}$ cacodylate buffer. After washing, they were postfixed in $2 \%$ osmium tetroxide with the same buffer, dehydrated in a graded ethanol series and embedded in Epon. Semithin sections were stained with methylene blue and azure II for light microscopic observation. Ultrathin sections were double stained with uranyl acetate and lead citrate and examined in a JEOL 100CX transmission electron microscope.

\section{Immunofluorescence analysis}

Cells were pelleted, pre-embedded in Histogel $^{\mathrm{TM}}$ (ThermoScientific) and subsequently, paraffin-embedded. Dewaxed sections were blocked with normal goat serum (1:5) in 10\% BSA for 30min, prior to incubation with primary antibodies (Table 1) diluted in 5\% BSA, $\mathrm{ON}$ at $4{ }^{\circ} \mathrm{C}$. Then, sections were incubated with Alexa Fluor-conjugated secondary antibodies, diluted 1:500 in 5\% BSA for 45min. Washes were performed with PBS and slides incubated with 4.6-diamidine2-phenylindolendihydrochoride $100 \mu \mathrm{g} / \mathrm{mL}$ for $10 \mathrm{~min}$. Slides were mounted in Vectashield ${ }^{\oplus}$ (Vector Laboratories) and observed by fluorescence microscopy (Zeiss Axio Imager Z1 Apotome). For negative controls, primary antibody was replaced by PBS.

\section{Western blotting}

Cells were incubated with lysis buffer 17 (R\&D Systems) and 3 $\mathrm{mmol} / \mathrm{L}$ sodium vanadate, $20 \mathrm{mmol} / \mathrm{L}$ sodium fluoride, $1 \mathrm{mmol} / \mathrm{L}$ phenylmethylsulphonyl fluoride. Protein concentration was determined by the $\mathrm{DC}^{\mathrm{TM}}$ Protein Assay (Bio-Rad) and $15 \mu \mathrm{g}$ of lysate were separated in $8 \%$ acrylamide/bis acrylamide (Sigma) SDS-PAGE gel. Gels were transferred onto a nitrocellulose membrane, blocked with $5 \%$ fat dry milk and incubated with primary antibodies, $\mathrm{ON}$ at $4^{\circ} \mathrm{C}$ (Table 1). Membranes were then incubated with secondary antibodies conjugated with horseradish peroxidase (DAKO) at 1:2000 for 1h. Analysis was performed by chemiluminescence using the ECL Western blotting detection reagent and films (GE Healthcare). Actin expression was used as a reference gene.

\section{Chromosome analysis}

Chromosome analysis was carried out at P5 and P7. Briefly, cells in the exponential growth phase were exposed to colcemid $(10 \mu \mathrm{g} / \mathrm{mL})$ for $2-4 \mathrm{~h}$ at $37^{\circ} \mathrm{C}$. Following hypotonic treatment and fixation the slides were made by dropping cells on glass slides and stained by Giemsa. Karyotyping was performed according to the International System for Human Cytogenetic Nomenclature [22].

\section{Results}

\section{Characterization of the gastric tissue: Necropsy, histopathology and immunohistochemical findings}

Macroscopic examination of the stomach revealed marked wall thickening, accompanied by decrease in the number of rugae, foci of erosion and ulceration of the mucosa, involving the gastric body (Figure 1A). The serosa was indurated, and pale and the regional lymph nodes were enlarged. The remaining organs showed no macroscopic changes. Microscopically, an irregular neoplastic lesion ulcerating the mucosa and invading the muscular and serous layers of the stomach was identified (Figure 1B and 1D). The lesion consisted of an epithelial neoplastic population arranged in nests, irregular groups, isolated cells or rarely forming small incipient tubules, triggering intense desmoplastic reaction. The neoplastic cells presented large, round to oval nuclei, containing 1-3 prominent nucleoli and acidophilic cytoplasm, sometimes filled by a macro vacuole that pushed the nucleus against the periphery (signet ring cells) and occasionally stained positive for PAS-AB (Figure 1C). Mitotic figures (7 per high power field) were frequent some of which atypical. Multiple neoplastic vascular emboli were observed. Histological examination of the lung, pancreas, adrenal gland and mesentery revealed cells morphologically identical to those described in the stomach, within the parenchyma and vascular structures (Figure $1 \mathrm{E}$ and $1 \mathrm{~F}$ ). Based on histopathological findings, the neoplasm was classified as signet ring cell carcinoma [17] and diffuse gastric carcinoma [18].

Immunohistochemistry of neoplastic gastric tissue revealed strong to moderate cytoplasm AE1/AE3 staining, affecting more than $50 \%$ of the neoplastic cell population (Figure 1G). Neoplastic cells 
were completely devoid of vimentin immunolabelling (Figure $1 \mathrm{H}$ ). E-cad expression was abnormal, characterized by absence of staining in $40 \%$ of the neoplastic cells, cytoplasmic distribution in $40 \%$ and discontinuous membrane staining in $20 \%$ of the neoplastic cells (Figure 1I).

\section{Tissue culture and short-term primary culture characterization}

Cells from gastric neoplasm were obtained by gentle mechanical and enzymatic dissociation. The first passage occurred after 10 days, when the cultured cells reached $90 \%$ of confluence. Cells grew without interruption over 27 days and 7 passages. After these passages, it is not possible to maintain cell growth. The proliferative activity of the cells was evaluated in different growth media and results showed that MEM $\alpha$ was preferred for cell proliferation (Figure 2A). Microbiology contamination test showed negative results in all time points evaluated.

\section{Growth characteristics}

Cells grew in adherent monolayer and exhibited polygonal and fusiform morphology (Figure 2B). Occasionally multiple and small, optically empty vacuoles were visible in cell cytoplasm. Succeeding expansion, cells became elongated, spindle-shaped and colonized the whole culture. No significant differences in successive passages were observed. Cellular-growth curves using Trypan Blue (Figure 2C) and Presto Blue cell viability (Figure 2D) assays revealed cell growth dynamics. In the Trypan blue assay, during the first $48 \mathrm{~h}$ of incubation the population density was almost constant (lag phase) after, there was an exponential increase in the number of viable cells (log phase). At 96h, the cell growth reached its peak and decreased. In the Presto Blue

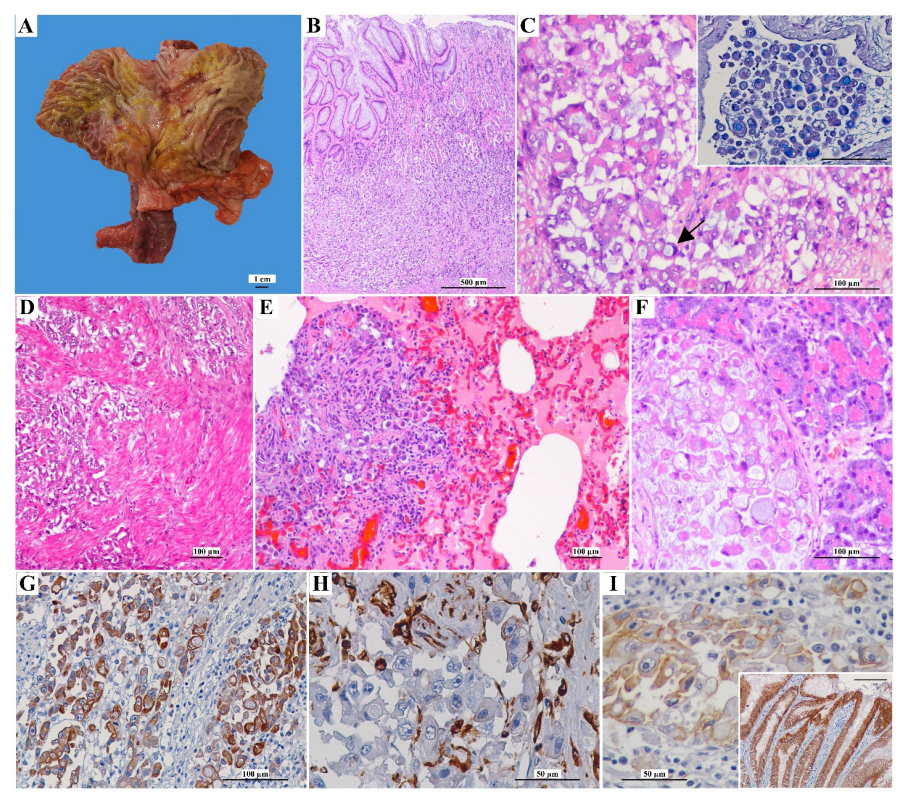

Figure 1. Morphological and immunohistochemical features of the gastric neoplasm. (A) Gross aspect of the gastric neoplasm involving most of stomach body. Note the ulceration area (delimited area) and the foci of erosion. (B) and (D) Microscopic examination revealing a gastric neoplasm that ulcerates the mucosa and invades the muscular (H\&E). (C) Neoplastic epithelial cells have pale and large nuclei, prominent nucleoli and acidophilic cytoplasm sometimes filled by a macrovacuole (arrow) (H\&E). Inset: Neoplastic emboli shows positive PAS-AB staining in cytoplasmic vacuoles (bar $=100 \mu \mathrm{m})$. (E) Pulmonary metastasis (H\&E). (F) Pancreatic metastasis (H\&E). (G) Strong cytoplasm immunopositivity in most neoplastic cells for AE1/AE3 (IHQ). (H) Vimentin immunoexpression was negative in neoplastic cell population (IHQ). (I) Abnormal E-cad immunoexpression in neoplastic epithelial cells (IHQ). Inset: adjacent normal gastric mucosa has been used as positive control for E-cad (bar $=100 \mu \mathrm{m})$
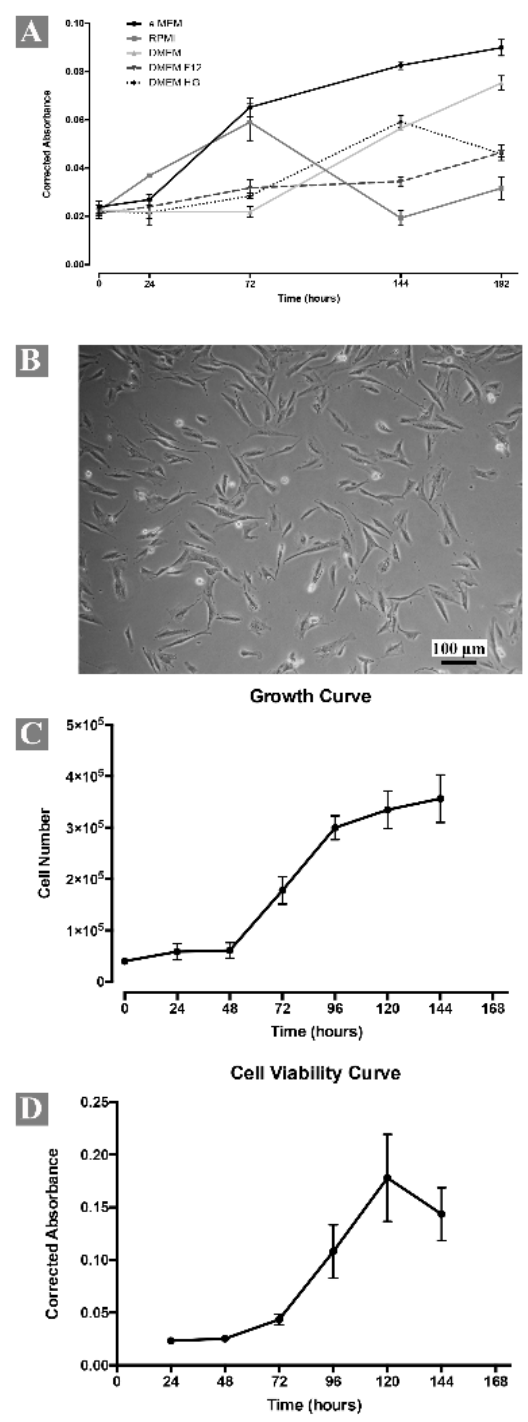

Figure 2. Morphological and growth characteristics of the short-term primary culture (all measures were performed in triplicate). (A) Growth curve of cells at passage 2 (P2) in different standard culture media. Note the higher metabolic activity of the cells when MEM $\alpha$ was used as culture medium. (B) Cells at passage 4 (P4) growing in monolayer and exhibiting polygonal or fusiform morphology. (C) Growth curve determined by Trypan Blue ${ }^{\circledR}$ exclusion assay of cells from P4. (D) Cell viability curve determined from Presto Blue ${ }^{\circledR}$ viability assay of cells from P4. All measures were performed in triplicate

cell viability assay, the lag phase is also present during the first $48 \mathrm{~h}$ of incubation, but log phase ends at $120 \mathrm{~h}$. Although the number of cells arrested its proliferation at $96 \mathrm{~h}$ the cells remained metabolically active up to $120 \mathrm{~h}$. Population doubling time was about $45,88 \mathrm{~h}$ ( $\mathrm{SD} \pm 2,88$, $\mathrm{N}=5$ ).

\section{Morphological studies}

Semithin sections disclosed round to oval cells with large indented nuclei with 1-2 prominent nucleoli. Most cells exhibited a single nucleus with occasional binucleated cells. The cytoplasm contained multiples vacuoles, optically empty. Sometimes, the vacuoles push the nucleus to the periphery, conferring a signet ring cell appearance to the cell (Figure S1). Ultrastructurally, the cells presented small and sparse cytoplasm membrane projections and 
several cytoplasm vesicles, with heterogenous content (Figure 3A). Small and thin mitochondria were abundant. Rough endoplasmic reticulum cisterns were flattened, sometimes with dilated portions containing finely granular material (Figure 3B).

\section{Analysis of epithelial markers and vimentin}

Regarding AE1/AE3 (Figure 4A) and E-cad (Figure 4C) the immunoexpression levels were like those of negative control and auto-fluorescence was suspected. However, immunofluorescence revealed a positive labelling for vimentin (Figure 4B). To confirm immunofluorescence results, Western blotting was performed. For vimentin a strong band near 48 and $63 \mathrm{kDa}$ was observed. Regarding AE1/AE3, a single band at approximately 48 and $25 \mathrm{kDa}$ was demonstrated. Western blotting also revealed that cultured cells did not express E-cad marker (Figure 4D).

\section{Chromosome analysis}

The frequency of normal and aneuploid cells is given in Table 3. Cells with 78 chromosomes (77 acrocentric and 1 submetacentric X) were found in both passages (Figure 5A). Most cells were aneuploid with a wide range of chromosome numbers from 44 to 156 and 41 to 175 in the P5 and P7, respectively (Figure 5B and 5C). Regarding to ploidy levels, the short-term primary cell culture was predominantly hypodiploid, with a modal number of $70, \mathrm{XY} / 75, \mathrm{XY}$ in $\mathrm{P} 5$ and 75 , $\mathrm{XY} / 76, \mathrm{XY}$ in P7 (Table 4).

\section{Discussion}

Gastric carcinomas are the most common gastric neoplasms that affect humans [18] and dogs [2,3]. In vivo and in vitro experiments using established human gastric cancer cell lines play an important role in understanding the molecular mechanisms involved in gastric

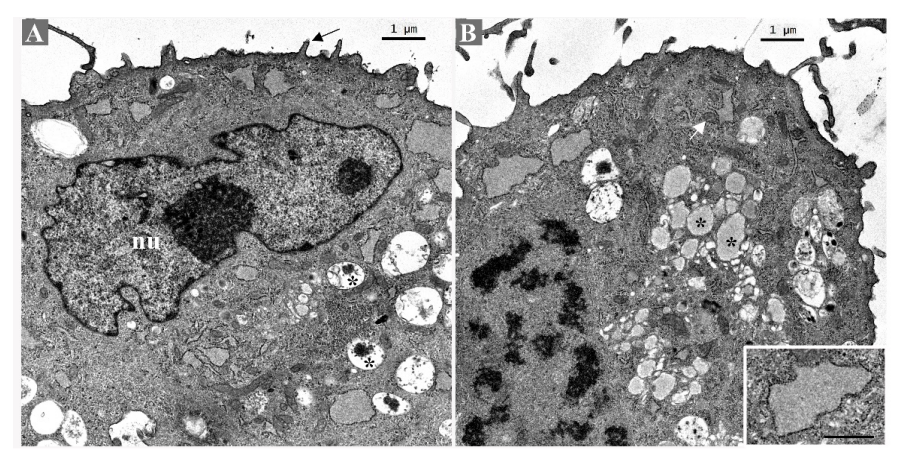

Figure 3. Ultrastructural appearance of the short-term primary culture. (A) Irregular nucleus (nu) with prominent nucleoli. Vesicles with heterogeneous electron-dense material (asterisks). Cytoplasmic membrane projections (arrow). (B) Pre-metaphase. Vesicles with homogeneous and moderately electron-dense content (asterisks). Mitochondria (arrow white) are abundant. Flat rough endoplasmic reticulum cisternae with dilated portions (inset)

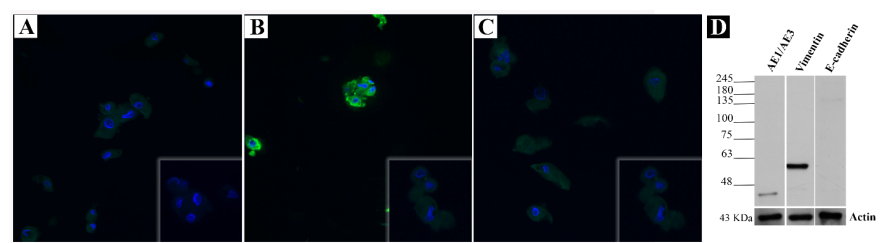

Figure 4. Immunofluorescence and Western blotting of the short-term primary culture. (A) Immunofluorescence detection of AE1/AE3, (B) Vimentin and (C) E-cad in the primary culture (magnification 200x). Insets show the negative controls. (D) Western blot analysis of AE1/AE3, Vimentin and E-cad protein levels in the primary culture. Cells showing strong vimentin expression and weak AE1/AE3 expression. E-cad expression was absent

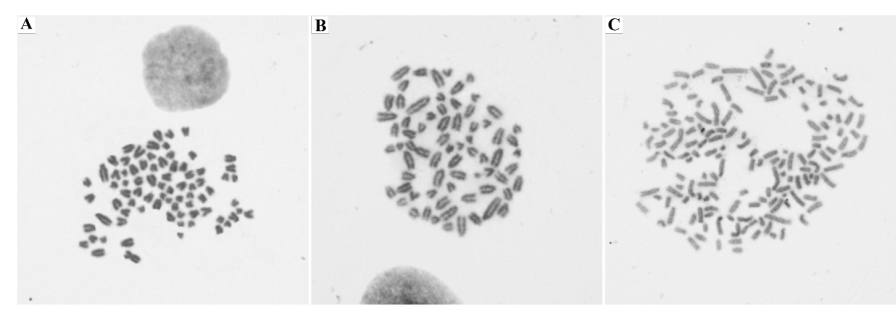

Figure 5. Karyotype of the short-term primary culture (magnification 100x). (A) Cell with chromosomes (77 acrocentric and 1 submetacentric) from passage 7. (B) Hypodiploid cell from passage 5 (70, XY). (C) Hyperdiploid cell from passage 7 (153, XY)

Table 3. Frequency of normal and aneuploid cells in the two different cell generations (P5 and P7)

\begin{tabular}{|l|c|c|}
\hline \multirow{2}{*}{} & \multicolumn{2}{|c|}{ Passage nr. } \\
\cline { 2 - 3 } Metaphase nr. & 5 & 7 \\
\hline \% Cells 78, XY & 14 & 26 \\
\hline \% Hypodiploid cells & 68 & 12 \\
\hline \% Hyperdiploid cells & $(44-77, \mathrm{XY})$ & 61 \\
\hline \% Near tetraploid/tetraploid cells & 10 & $(41-77 \mathrm{XY})$ \\
\hline
\end{tabular}

Table 4. Distribution of the number of chromosomes in hypodiploid cells in the two different cell generations (P5 and P7)

\begin{tabular}{|c|c|c|}
\hline Passage nr. & $\begin{array}{c}\text { Variation in chromosome } \\
\text { number }\end{array}$ & Modal number \\
\hline $\mathbf{5}$ & $44-77, \mathrm{XY}[34]$ & $70, \mathrm{XY}[6] / 75, \mathrm{XY}[6]$ \\
\hline $\mathbf{7}$ & $41-77, \mathrm{XY}[16]$ & $75, \mathrm{XY}[3] / 76, \mathrm{XY}[3]$ \\
\hline
\end{tabular}

carcinogenesis and to the development of new therapies [11]. However, the establishment of human gastric cancer cell lines from fresh tissues remains a challenge due to gastric stromal factors interference in the epithelial growth rate $[23,24]$. In addition, passage numbers alter in vitro protein expression and mutation behaviour [23,25]. CGCs show strong similarities with HGCs [3] thus, derived cell lines may provide a unique opportunity to act as a model for gastric cancer translational research [26]. Herein, we report the establishment of a short-term primary culture derived from a canine diffuse gastric adenocarcinoma and provide evidences for its characterization.

For successful culture of an organ or tissue it is indispensable to provide a suitable culture microenvironment for cell proliferation and differentiation [27]. It is recognized that majority of cells in vivo secrete endogenous growth factors to stimulate their own proliferation. Therefore, similar conditions may be achieved using the appropriate media formulations during cell culture [23,24]. Gastric cells are usually cultured in RPMI1640 [9,10,12,24] and DMEM [28], although other media such has DMEM/F-12 [13,20] and MEMa [29] have also been used. Nevertheless, information about the potential effects of culture media on the growth and differentiation of gastric cells remains limited. Recently, Huang et al. found no differences in cellular morphology and proliferation rates of a commercial human gastric cancer cell line (SGC7901) cultured in DMEM and RPMI1640 [30]. In this context, we investigate the effects of different media on cell morphology and proliferation and find no morphological differences but, the proliferative activity was higher when these cells were cultured in MEMa, may be due to its specific composition. Glucose is a central source of cellular energy and its amount vary between the different culture medium available from 1 to $4.5 \mathrm{~g} / \mathrm{L}$ [27]. 
Several studies in human mesenchymal stem cells have demonstrated that high levels of glucose induce cellular senescence while low levels enhanced cell proliferation [31,32]. Curiously, MEMa medium has the lowest concentration of glucose. Further studies are needed to understand cell metabolism and glucose effect on cell proliferation of this specific short-term primary culture.

Most cultures of diffuse-type gastric carcinoma are difficult to grow as long-term cultures but the reason for this is not completely understood $[9,33]$. The major problem when starting a gastric cell culture is the contamination by stromal fibroblasts which display potential cytotoxic effects and arrest the epithelial cells growth [34]. However, in the case of diffuse gastric carcinomas it is postulated that the development of this type of tumour depends on the secretion of growth-promoting factors produced by stromal cells. This could justify the difficulties of growing cells from this type of tumour in "fibroblasts-free" cultures $[35,36]$ and also explain the reason why this canine cell culture was maintained only for 7 passages, after what they became senescent.

Morphologically, cultured cells were polygonal and fusiform and grew in adherent monolayer. These findings are consistent with other human primary gastric adenocarcinomas cell lines derived from diffuse gastric carcinomas (GP 202) [37] and signet-ring cell carcinomas (SNU-601 and SNU-668) [10].

To elucidate and verify the histogenesis of this primary culture electron microscopy studies were performed. Ultrastructurally, cells were round and presented irregular nucleus and prominent nucleoli. Presence of cells with cytoplasmic vacuoles pushing the nucleus towards the periphery is a typical feature of in vitro cultured diffuse gastric carcinomas $[37,38]$ and support the gastric origin of this short-term culture. Furthermore, the presence of cells with a signet-ring shape in primary neoplasm and in culture reinforces the biological similarities between the original neoplasm and the experimental in vitro model.

Western blot analysis demonstrated that cultured cells expressed the epithelial marker AE1/AE3, similarly to the original neoplasm. However, in culture, the cells have lost the expression of epithelial specific gene E-cad and acquired the expression of vimentin, an intermediate filament of mesenchymal stem cells. Epithelial-tomesenchymal transition (EMT) is a critical event in cancer metastasis, characterized by the combined loss of epithelial cell junction proteins, such as E-cad, and the gain of mesenchymal markers such as vimentin [39]. Our results suggest that during the establishment of the cell culture, cells acquired a fibroblastic phenotype via EMT, as previously described by Xu et al. [12] in a primary human signet ring gastric cancer cell line. The acquisition of mesenchymal phenotype also comprises the increase of cell motility, invasiveness and metastatic capabilities [40], thus reinforcing that cultured cells also may have metastatic potential. Further studies are required to evaluate the metastatic potential of this specific short-term culture.

Chromosome analysis was used primarily to observe if this canine short-term culture had cytogenetic malignant characteristics. Since tumour specimens are often a complex mixture of normal, benign and neoplastic cells, the origin of a particular cell is difficult to determine and therefore, karyotype analysis is of considerable interest [41]. Furthermore, chromosome analysis at different passages is useful for monitoring the chromosome stability during expansion. In the present case, the primary culture presented a predominantly aneuploid nonclonal karyotype, with a wide variation in chromosome numbers, as like in other human gastric cancer cell lines derived from diffuse gastric carcinomas $[38,42]$. Both, aneuploidy and chromosome instability
(CIN) have been recognized as the hallmarks of cancer however, their role in tumour initiation and progression is unclear. Aneuploidy and CIN provide genetic variation which allow the environmental adaptation of cells, but it has been also associated to detrimental effects on cellular fitness, triggering cell cycle arrest or apoptosis [43]. In gastric carcinomas, aneuploidy has been correlated with high proliferative activity, metastatic potential and therefore, poor prognosis [44].

\section{Conclusion}

We have established for the first time a short-term primary culture from a spontaneously occurring canine diffuse gastric carcinoma. In vitro, the culture maintains some of the characteristics of the original tumour which could provide a useful model for studying the morphological characteristics, differentiation and metastasis. Although, a long-term culture has not been established important remarks have been documented that should be considered in the future providing more detailed investigations in this area of veterinary oncology.

\section{Acknowledgment}

A.R. Flores (SFRH/BD/116373/2016), A.R. Caseiro (SFRH/ $\mathrm{BD} / 101174 / 2014$ ) and R. Matos (SFRH/BD/131159/2017) acknowledge FCT, the Portuguese Foundation for Science and Technology, for financial support. IPATIMUP integrates the i3S Research Unit, which is partially supported by FEDER through the Operational Programme for Competitiveness Factors-COMPETE and National Funds through the Portuguese Foundation for Science and Technology (FCT), under the project number PEst-C/SAU/LA0003/2013. CECA-ICETA is partially supported by FEDER through the Operational Programme for Competitiveness Factors-COMPETE and National Funds through the Portuguese Foundation for Science and Technology (FCT) under the project number PEst-OE/AGR/UI0211/2011. This research was also supported by Programa Operacional Competitividade e Internacionalização (P2020), Fundos Europeus Estruturais e de Investimento (FEEI) and FCT with the project "BioMate - A novel bio-manufacturing system to produce bioactive scaffolds for tissue engineering" with reference PTDC/EMS-SIS/7032/2014.

\section{Conflicts of interest}

The authors have declared that no competing interests exist.

\section{References}

1. Jemal A, Center MM, DeSantis C, Ward EM (2010) Global patterns of cancer incidence and mortality rates and trends. Cancer Epidemiol Biomarkers Prev 19: 1893-1907.

2. Amorim I, Taulescu MA, Day MJ, Catoi C, Reis CA, et al. (2016) Canine gastric pathology: A review. J Comp Pathol 154: 9-37.

3. Hugen S, Thomas RE, German AJ, Burgener IA, Mandigers PJJ (2017) Gastric carcinoma in canines and humans, a review. Vet Comp Oncol 15: 692-705. [Crossref]

4. AbdelMageed MA, Betancur-Boissel M, Foltopoulou P, Muthupalani S, Fox JG, et al (2015) Abstract 5142: A naturally occurring model for gastric cancer. Cancer Research. 75: 5142 .

5. Louzada S, Adega F, Chaves R (2012) Defining the sister rat mammary tumor cell lines HH-16 cl.2/1 and HH-16.cl.4 as an in vitro cell model for Erbb2. PLoS One 7: e29923. [Crossref]

6. Gazdar AF, Girard L, Lockwood WW, Lam WL, Minna JD (2010) Lung cancer cell lines as tools for biomedical discovery and research. J Natl Cancer Inst 102: 13101321. [Crossref]

7. Vargo-Gogola T, Rosen JM (2007) Modelling breast cancer: one size does not fit all Nat Rev Cancer 7: 659-672. [Crossref]

8. Shoemaker RH (2006) The NCI60 human tumour cell line anticancer drug screen. Nat Rev Cancer 6: 813-823. [Crossref] 
9. Park JG, Frucht H, LaRocca RV, Bliss DP Jr, Kurita Y, et al. (1990) Characteristics of cell lines established from human gastric carcinoma. Cancer Res 50: 2773-2780. [Crossref]

10. Park JG, Yang HK, Kim WH, Chung JK, Kang MS, et al. (1997) Establishment and characterization of human gastric carcinoma cell lines. Int $J$ Cancer 70: 443-449. [Crossref]

11. Ku JL, Kim KH, Choi JS, Kim SH, Shin YK, et al. (2012) Establishment and characterization of six human gastric carcinoma cell lines, including one naturally infected with Epstein-Barr virus. Cell Oncol (Dordr) 35: 127-36.

12. Xu X, Qian LJ, Su XY, He KF, Jin KT, et al. (2015) Establishment and characterization of GCSR1, a multi-drug resistant signet ring cell gastric cancer cell line. Int J Oncol 46: 2479-2487. [Crossref]

13. Xu H, Peng JG, Zhuang YF, Chen JJ, Luo QC, et al. (2016) Establishment and characterization of an expanding-type gastric cancer cell line by Ming's classification. Oncol Rep 36: 3030-3036. [Crossref]

14. Motoyama T, Hojo H, Watanabe H (1986) COMPARISON OF SEVEN CELL LINES DERIVED FROM HUMAN GASTRIC CARCINOMAS. Pathology International 36 65-83.

15. Chen MC, Lee AT, Soll AH (1991) Mitogenic response of canine fundic epithelial cells in short-term culture to transforming growth factor alpha and insulinlike growth factor I. J Clin Invest 87: 1716-1723.

16. Pausawasdi N, Ramamoorthy S, Stepan V, del Valle J, Todisco A (2000) Regulation and function of $\mathrm{p} 38$ protein kinase in isolated canine gastric parietal cells. Am J Physiol Gastrointest Liver Physiol 278: G24-31. [Crossref]

17. Head K, Cullen J, Dubielzig R, Else R, Misdorp W (2003) Histological Classification Tumors of the Alimentary System of Domestic Animals. Armed Forces Institute of Pathology in cooperation with the American Registry of Pathology and the World Health Organization Collaborating Center for Worldwide Reference on Comparative Oncology, Washington DC. 2003.

18. Lauren P (1965) The two histological main types of gastric carcinoma: diffuse and so-called intestinal-type carcinoma. an attempt at a histo-clinical classification. Acta Pathol Microbiol Scand 64: 31-49.

19. Jawhari A, Jordan S, Poole S, Browne P, Pignatelli M, et al. (1997) Abnorma immunoreactivity of the E-cadherin-catenin complex in gastric carcinoma: relationship with patient survival. Gastroenterology 112: 46-54. [Crossref]

20. Smoot DT, Sewchand J, Young K, Desbordes BC, Allen CR, et al. (2000) A method for establishing primary cultures of human gastric epithelial cells. Methods Cell Sci 22: $133-136$.

21. Roth V (2006) Doubling Time Calculator. http://wwwdoubling-timecom/computephp.

22. Nomenclature ISCoHC, McGowan-Jordan J, Simons A, Schmid M (2016) ISCN: An International System for Human Cytogenomic Nomenclature (2016): Karger.

23. Rutten M, Campbell D, Luttropp C, Fowler W, Hawkey M, et al. (1996) A method for the isolation of human gastric mucous epithelial cells for primary cell culture: A comparasion of biopsy vs surgical tissue. Methods in Cell Science. 18: 269-281.

24. Aziz F, Yang X, Wen Q, Yan Q (2015) A method for establishing human primary gastric epithelial cell culture from fresh surgical gastric tissues. Mol Med Rep 12: 2939-2944.

25. Liu G, Chai Y, Zhu X, Zhang Q (2008) Explants culture of gastric tissue continuosly in a small amount of medium. Cancer Research Prevention and Treatment. 2: 147-148.
26. Knapp DW, Waters DJ (1997) Naturally occurring cancer in pet dogs: important models for developing improved cancer therapy for humans. Mol Med Today 3: 8-11.

27. Wu X, Lin M, Li Y, Zhao X, Yan F (2009) Effects of DMEM and RPMI 1640 on the biological behavior of dog periosteum-derived cells. Cytotechnology 59: 103-111.

28. Murakami H, Nakanishi H, Tanaka H, Ito S, Misawa K, et al. (2013) Establishmen and characterization of novel gastric signet-ring cell and non-signet-ring cell poorly differentiated adenocarcinoma cell lines with low and high malignant potential. Gastric Cancer 16: 74-83.

29. Yanagihara K, Seyama T, Tsumuraya M, Kamada N, Yokoro K (1991) Establishmen and characterization of human signet ring cell gastric carcinoma cell lines with amplification of the c-myc oncogene. Cancer Res 51: 381-386. [Crossref]

30. Huang Z, Shao W, Gu J, Hu X, Shi Y, et al. (2015) Effects of culture media on metabolic profiling of the human gastric cancer cell line SGC7901. Mol Biosyst 11: 1832-1840. [Crossref]

31. Stolzing A, Coleman N, Scutt A (2006) Glucose-induced replicative senescence in mesenchymal stem cells. Rejuvenation Res 9: 31-35.

32. Kim HS, Park JW, Yeo SI, Choi BJ, Suh JY, et al. (2006) Effects of high glucose on cellular activity of periodontal ligament cells in vitro. Diabetes Res Clin Pract 74 : 41-47.

33. Sekiguchi M, Sakakibara K, Fujii G (1978) Establishment of cultured cell lines derived from a human gastric carcinoma. Jpn J Exp Med 48: 61-68. [Crossref]

34. Chew CS, Ljungström M, Smolka A, Brown MR (1989) Primary culture of secretagogue-responsive parietal cells from rabbit gastric mucosa. Am J Physiol 256 G254-263. [Crossref]

35. Delinassios JG (1987) Fibroblasts against cancer cells in vitro. Anticancer Res 7: 1005 1010. [Crossref]

36. Yashiro M, Chung YS, Sowa M (1994) Role of orthotopic fibroblasts in the development of scirrhous gastric carcinoma. Jpn J Cancer Res 85: 883-886. [Crossref]

37. Gartner F, David L, Seruca R, Machado JC, Sobrinho-Simões M (1996) Establishment and characterization of two cell lines derived from human diffuse gastric carcinomas xenografted in nude mice. Virchows Arch 428: 91-98. [Crossref]

38. Dippold WG, Kron G, Boosfeld E, Dienes HP, Klingel R, et al. (1987) Signet ring stomach cancer: morphological characterization and antigenic profile of a newly established cell line (Mz-Sto-1). Eur J Cancer Clin Oncol 23: 697-706. [Crossref]

39. Thiery JP, Acloque H, Huang RY, Nieto MA (2009) Epithelial-mesenchymal transitions in development and disease. Cell 139: 871-890. [Crossref]

40. Mani SA, Guo W, Liao MJ, Eaton EN, Ayyanan A, et al. (2008) The epithelialmesenchymal transition generates cells with properties of stem cells. Cell 133: 704 715. [Crossref]

41. Ohnuki Y, Marnell MM, Babcock MS, Lechner JF, Kaighn ME (1980) Chromosomal analysis of human prostatic adenocarcinoma cell lines. Cancer Res 40: 524-534. [Crossref]

42. Yashiro M, Chung YS, Nishimura S, Yamada N, Sawada T, et al. (1995) [Establishment of a new scirrhous gastric cancer cell line OCUM-2M from a primary gastric tumor] Nihon Shokakibyo Gakkai Zasshi 92: 199-205.

43. Giam M, Rancati G (2015) Aneuploidy and chromosomal instability in cancer: a jackpot to chaos. Cell Div 10: 3. [Crossref]

44. Baba H, Korenaga D, Kakeji Y, Haraguchi M, Okamura T, et al. (2002) DNA ploidy and its clinical implications in gastric cancer. Surgery 131: S63-70. [Crossref]

Copyright: ( 2019 Flores AR. This is an open-access article distributed under the terms of the Creative Commons Attribution License, which permits unrestricted use, distribution, and reproduction in any medium, provided the original author and source are credited. 